\title{
Social emotion and patient safety: an important and understudied intersection
}

\author{
Jane Heyhoe, ${ }^{1}$ Rebecca Lawton (1) ${ }^{1,2}$
}

'Quality and Safety Research Group, Bradford Institute for Health Research, Bradford, UK ${ }^{2}$ School of Psychology, University of Leeds, Leeds, UK

\section{Correspondence to} Dr Jane Heyhoe, Quality and Safety Research Group, Bradford Institute for Health Research, Bradford BD9 6RJ, UK; jane.heyhoe@bthft.nhs.uk

Accepted 10 March 2020 Published Online First 26 March 2020

\section{Linked}

- http://dx.doi.org/10.1136/ bmjgs-2019-010110

- http://dx.doi.org/10.1136/ bmjqs-2019-010179

\section{Check for updates}

(C) Author(s) (or their employer(s)) 2020. No commercial re-use. See rights and permissions. Published by BMJ.

To cite: Heyhoe J, Lawton R BMJ Qual Saf

2020;29:787-789.
Until the late 1990s, models of decision making and behaviour in the psychological literature largely ignored the role of emotion. With the work of influential authors, ${ }^{1-3}$ among others, came the recognition and evidence that our decisions are not always rational. We rely on heuristics or rules of thumb that can accumulate with experience and exposure and that help us to be more efficient (most of the time) but also prone to bias. ${ }^{4}$ At the same time, social psychologists seeking to understand what drives our behaviour were also beginning to recognise that, while the costs and benefits of adopting a particular behaviour (eg, smoking or running) were important motivators, the anticipated and actual feelings associated with engaging in these behaviours were often more important predictors of future behaviours. ${ }^{5}$ For example, people who felt miserable and embarrassed when running were less likely to run again, despite the knowledge that it was good for them. What was also becoming obvious was that people are not all that good at understanding how powerful emotions can be in driving their behaviour. Insightful work by Sayette and colleagues, ${ }^{6}$ for example, demonstrated that if we ask smokers who were not currently craving a cigarette (cold emotional state) if they could give up, they often said they could, but when craving a cigarette (in a hot emotional state), they were much more likely to be accurate about their inability to give up. There is also evidence that a hot-cold empathy gap is relevant in medical decision making. ${ }^{7}$ This last point has important implications for the study of emotions, highlighting that we may need to be cautious about interpreting findings from studies that ask people to recall or imagine how emotion may or may not have influenced their judgements or behaviour or indeed how it will influence their future behaviour.

In 2016, we published a call to action, asking researchers if they were 'brave enough to scratch beneath the surface' to explore the role of emotion in patient safety. ${ }^{8}$ We highlighted the importance of emotion as a precursor to safe or unsafe care, but we also highlighted that patient safety events are a very important source of emotion in themselves. In that same year, this journal published the findings of two randomised experiments examining emotion as a precursor to clinical judgement. In these studies, vignettes containing identical clinical content, but involving patients who would elicit either a neutral or negative physician response, were presented to 63 trainee general practitioners $^{9}$ and 74 trainee hospital doctors. ${ }^{10}$ Findings revealed that, while there was no difference in the length of time taken to reach a diagnosis, 'negative' patients were rated lower than neutral patients for likeability and had lower rates of diagnostic accuracy.

This issue of BMJ Quality and Safety includes two studies by Isbell and colleagues, ${ }^{11} 12$ which also focus on emotion as a precursor to safe decision making. Both studies took place in emergency departments in the USA, an emotionally charged field of practice. These studies are exciting, adding to a growing body of literature asking challenging research questions about how patients elicit emotions that impact on decision making and patient safety. The first study ${ }^{11}$ investigated the impact of emotionally evocative patients and asked 94 clinicians to recall three patient encounters, including one that elicited anger/ frustration/irritation ('angry encounter'), one that generated happiness/satisfaction/ appreciation ('positive encounter') and 
one involving a patient with a mental health condition ('mental health encounter'). Clinicians were then asked to rate their emotions and engagement in each encounter and to report their perception of whether and how their emotions impacted their clinical decision making and behaviour. The findings suggest that patients who display anger and those with mental health problems are associated with emergency department physicians and nurses feeling sad, fatigued and angry. This, in turn, is reported to lead to less effective care, primarily due to the fact that the healthcare staff spend less time and are less thorough in their history taking, examinations and treatment decisions. These impacts of negative feelings in response to patients were common to both studies.

In the second study, ${ }^{12}$ interviews with 86 clinicians were used to explore patient-level, hospital-level and system-level triggers of emotion. Clinicians were able to identify the discrete emotions they experience and the triggers in the clinical setting that elicited these feelings. While patients evoked a broad range of positive and negative feelings (most commonly anger, sadness, gratification, anxiety and frustration), hospital-level and system-level factors were most often linked to negative feelings. Clinicians in this study understood the impact that these feelings had on their decision making, and they tried to take steps to address this, including suppressing emotion, detaching themselves and attempting to reappraise the situation.

Earlier work exploring diagnostic and case management decisions provides further evidence that clinicians can recognise and reflect on the environmental triggers of emotion and how these affect their judgement and actions. ${ }^{13}$ However, this work also demonstrated that negative emotions did not necessarily lead to less thorough decision making. Clinicians reported that both positive feelings such as 'calm', 'comfortable' and 'assertive' and negative feelings, such as 'nervous', 'anxious' and 'uneasy', facilitated the ability to focus on specific details of the patient presentation or clinical task. This supports the need for research that looks more closely at the role that specific emotions (rather than a focus on positive and negative) play in improving or hindering judgement. For example, work by Lerner and Keltner ${ }^{14}$ suggests that specific emotions are linked to a set of appraisal tendencies that then impact on behaviour. For instance, while anger and anxiety are both negative emotions, the former prompts feelings of control and certainty and leads to greater risk taking, while the latter prompts feelings of low control and uncertainty associated with risk aversion.

Emotion in clinical settings is not only influenced by the patient; the healthcare professional will arrive at work in a certain mood and the department will have an emotional climate or tone, influenced by relationships and interactions in the team. Several studies have shown that exposure to rudeness and incivility affect clinical performance, ${ }^{15-17}$ and in the studies by Isbell and colleagues, healthcare providers discussed being influenced by emotion at a social as well as individual level. Factors such as consultants being perceived as uncooperative or unhelpful, the respect and appreciation felt towards colleagues as part of their 'community', and system-level factors such as 'overcrowding' were identified by clinicians as emotional triggers. Heyhoe $^{13}$ also explored the sources of emotion evoked by the physical and interpersonal environments. Physicians recalled the influence of 'interpersonal factors', such as unhelpful colleagues or those with different ideas about the best patient management strategy. When a sense of collaboration and harmony was created through colleagues discussing a case or sharing concerns about diagnostic uncertainty, this often increased confidence to pursue a plan to gather more information or action treatment. In contrast, when this did not occur, doctors often felt isolated, and this increased their awareness of potential threats to patient safety. Similarly, Nurok and colleagues ${ }^{18}$ identified that a less functional emotional climate was one where people were 'disengaged' and 'inappropriately tense' and that such a climate was associated with threats to outcomes (eg, poor handoffs, frequent distractions and lack of a shared mental model). This evidence is important in beginning to identify the core dimensions (cooperation, harmony, engagement and tenseness) that might signify a positive or negative emotional climate. Further, it also points to the potential value of measuring emotional climate as a real-time indicator of patient safety.

The research highlighted previously demonstrates the growing evidence that emotions can impact clinical performance and the safety of patient care. Researchers are beginning to gain knowledge of the types and sources of emotion experienced in clinical settings and identify potential strategies that may be useful for regulating any negative influence that emotions may have on interactions and decision making in healthcare. In order to continue to move forward in our understanding of the role of emotion at the level of the individual clinician and clinical teams, it will be helpful to draw on new models and theories of emotion and decision making from psychology in future research. The importance of dual-process theories (whether decisions are fast, intuitive and feeling-based, or slow, considered and cognitive-based), ${ }^{47}$ for example, are well recognised in the field of clinical decision making. Perhaps less well known is the emotions as social information ${ }^{19}$ theory that asserts that our judgements and actions are affected by the observation of emotion in others. This involves two different processes: inferential mechanisms (eg, you infer from senior nurses' nervousness that they think that the patient is suddenly deteriorating, which causes you to escalate the case yourself) and affective responses (eg, a colleague's lack of urgency about a case makes you feel calmer, and 
you decide that seeking the advice of another senior colleague is unnecessary).

Clinical decisions rarely occur in isolation. We must consider the social contexts in clinical environments and draw on theories of social emotion to help us better understand the influence of others' emotion on our own thoughts, feelings and, ultimately, our ability to deliver safe care. Furthering such understanding drives our own work within the NIHR Yorkshire and Humber Patient Safety Translational Research Centre. Exploring the role of social emotion in patient safety constitutes a new and emerging field of research with much still to learn. We call on the patient safety community to embrace the idea that emotions and emotional contexts exert important impacts on healthcare delivery. Characterising these impacts will inform strategies for supporting staff and delivering safer and more effective care to patients.

Twitter Rebecca Lawton@LawtonRebecca

Funding This work is funded by the National Institute for Health Research (NIHR) Yorkshire and Humber Patient Safety Translational Research Centre (NIHR Yorkshire and Humber PSTRC). The views expressed in this article are those of the author(s) and not necessarily those of the NHS, the NIHR, or the Department of Health and Social Care.

Competing interests None declared.

Patient consent for publication Not required.

Provenance and peer review Commissioned; internally peer reviewed.

\section{ORCID iD}

Rebecca Lawton http://orcid.org/0000-0002-5832-402X

\section{REFERENCES}

1 Epstein S. Integration of the cognitive and the psychodynamic unconscious. Am Psychol 1994;49:709-24.

2 Loewenstein GF, Weber EU, Hsee CK, et al. Risk as feelings. Psychol Bull 2001;127:267-86.

3 Slovic P, Peters E, Finucane ML, et al. Affect, risk, and decision making. Health Psychol 2005;24:S35-40.

4 Croskerry P. Clinical cognition and diagnostic error: applications of a dual process model of Reasoning. Adv Health Sci Educ Theory Pract 2009;14:27-35.
5 Lawton R, Conner M, McEachan R. Desire or reason: predicting health behaviors from affective and cognitive attitudes. Health Psychol 2009;28:56-65.

6 Sayette MA, Loewenstein G, Griffin KM, et al. Exploring the cold-to-hot empathy gap in smokers. Psychol Sci 2008;19:926-32.

7 Loewenstein G. Hot-cold empathy gaps and medical decision making. Health Psychol 2005;24:S49-56.

8 Heyhoe J, Birks Y, Harrison R, et al. The role of emotion in patient safety: are we brave enough to scratch beneath the surface? J R Soc Med 2016;109:52-8.

9 Mamede S, Van Gog T, Schuit SCE, et al. Why patients' disruptive behaviours impair diagnostic reasoning: a randomised experiment. BMJ Quality \& Safety 2017;26:13-18.

10 Schmidt HG, van Gog T, CE Schuit S, et al. Do patients' disruptive behaviours influence the accuracy of a doctor's diagnosis? A randomised experiment: Table 1. BMJ Qual Saf 2017;26:19-23.

11 Isbell LM, Tager J, Beals K, et al. Emotionally evocative patients in the emergency department: a mixed methods investigation of providers' reported emotions and implications for patient safety. BMJ Qual Saf 2020;29:802-13.

12 Isbell LM, Boudreaux ED, Chimowitz $\mathrm{H}$, et al. What do emergency department physicians and nurses feel? A qualitative study of emotions, triggers, regulation strategies, and effects on patient care. BMJ Qual Saf 2020;29:814-24.

13 Heyhoe J. Affective and cognitive influences on decision making in healthcare. PHD thesis. Leeds: University of Leeds, 2013.

14 Lerner JS, Keltner D. Beyond valence: toward a model of emotion-specific influences on judgement and choice. Cogn Emot 2000;14:473-93.

15 Katz D, Blasius K, Isaak R, et al. Exposure to incivility hinders clinical performance in a simulated operative crisis. BMJ Qual Saf 2019;28:750-7.

16 Riskin A, Erez A, Foulk TA, et al. Rudeness and medical team performance. Pediatrics 2017;139:1-3.

17 Riskin A, Erez A, Foulk TA, et al. The impact of Rudeness on medical team performance: a randomized trial. Pediatrics 2015;136:487-95.

18 Nurok M, Evans LA, Lipsitz S, et al. The relationship of the emotional climate of work and threat to patient outcome in a high-volume thoracic surgery operating room team. BMJ Qual Saf 2011;20:237-42.

19 Van Kleef GA. How emotions regulate social life: the emotions as social information (EASI) model. Curr Dir Psychol Sci $2009 ; 18: 184-8$. 